\title{
Reading Engagement Opportunities Of Education Students
}

\author{
Ethel D. Abao \\ Helen B. Boholano \\ Vinchita G. Quinto \\ Tizzamarrie M. Navarro \\ Cebu Normal University
}

\begin{abstract}
Reading is life. If $80 \%$ of man's activity involves reading, (Villamin 1994) then students be made conscious on what type and how the reading materials be chosen for personal and academic purpose. This study which utilized the descriptive-normative survey method aimed to find out the reading preferences and their effects to reading performance of the first year students in both Bachelor of Secondary and Bachelor of Elementary Education programs of Cebu Normal University. These were treated using the simple percentage and ranking with the Minitab software. Using the ranking, findings revealed that most of the students in the Bachelor in Elementary Education highly preferred the dictionary. This is followed by the newspapers, magazines, short stories, etc. On the other hand, the students in the Bachelor in Secondary Education students highly preferred the encyclopedia. This is followed by the magazines, short stories, textbooks, etc. Moreover, it is noted that there is no relationship between the students' reading preferences and their performance in reading. It means that their reading preferences do not have bearing nor effect on their reading performance. It is therefore concluded that reading is a personal responsibility. It is a matter of how one comprehends, analyzes, applies and creates new ideas from the written texts regardless of their preferences that leads them to develop critical thinking needed for them to function effectively in the society.
\end{abstract}

Keywords: Reading, Reading preferences, engagement and performance, descriptive normative survey, Cebu Normal University, Philippines

\section{Introduction}

Reading is life. It is a basic tool for learning across areas of discipline. Villamin et al (1998) said that $80 \%$ of the person's activity 
involves reading. We read recipes in cookbooks, instructions on how to do things, literature in medicine, menus in the restaurants, street signs and advertisements and many other printed forms in notices and announcements. It is a complex process whereby skills involve cognitive reasoning process associated with constructing meaning from text. Flavel (1987) said it is a general knowledge that guides the readers in monitoring their comprehension processes by selecting specific strategies to achieve goals. Different kinds of information require different kinds of processing and place different demands on the learner.

This note ushered to the valuable importance of a classroom teacher to observe each student in a variety of situations. This will allow him/her to draw conclusion about student performance relative to their individual strategies in reading as well as their reading preferences.

Daily family routines are central to all aspects of child development, yet little is known about the relationship between these family matters and specific aspects of children's literacy development, such as motivation to read (Arzubiaga, Rueda, \& Monzó, 2002). Motivation to read can be defined as the likelihood of engaging in reading or choosing to read (Gambrell, 2009, 2011). In the same study he added that motivation to read and reading achievement are higher when the classroom environment is rich in reading materials and includes books from an array of genres and text types, magazines, the Internet, resource materials, and real-life documents (Allington \& McGillFranzen, 1993; Guthrie et al., 2007; Kim, 2004; Neuman \& Celano, 2001).

What is preference without substance and what is substance without cultivating it? As observed, when students are required to read a chapter on the book or to present a relevant issue, oftentimes, they do not go beyond what is required. They only read what they like to read. In Arzubiaga, Rueda, and Monzó (2002), the understanding of how individuals become literate is continuously being revised in an effort to appreciate the process in all its complexity. One study of library behavior indicated however that most sophisticated students scanned or read parts of the book as they make decision about what to read. These students seemed to choose or reject a reading material based on personal preference on an emotional response. In college, reading materials become more abstract and contain a larger, more technical vocabulary. At this stage, the student must not only acquire new information but must also critically analyze the text and achieve an optimal reading rate based on the difficulty of the material and the purpose of reading. The researchers have observed that many students nowadays do not read extensively (making use of varied reading materials) and intensively (analyzing the content of the material) topics that are assigned to them for class interaction, rather they resort to asking from peers to share with them 
what the latter have read. Some have become contented with one reading material, others resort to simply reproduce what they encounter in some reading materials. Reading being a tool subject, the teachers/researchers are therefore concerned if this behavior of not being interested to read and with only one or very limited reading material would affect their performance. It is in this context that the proponents would like to determine the students' reading preferences and how these preferences affect their classroom reading performance.

\section{Short literature review}

It is deemed appropriate for a classroom teacher to observe each student in a variety of situations. This will allow the teacher to draw conclusions about students who fared well or poorly in varied teachinglearning activities. Some may prefer to read materials successfully when highly motivated. Others love to, but may have trouble with relating the materials to actual life experiences as well as with the other content areas probably because of the lack of background knowledge. Research indicates that students do perform differently according to combinations of such things as task, passage type, purpose, prior knowledge available (Villamin, et.al. 1998).

According to one writer in Forward Magazine (2000), ignorance cannot only be for those who lack knowledge and information but also with those who dare not read regarding issues of utmost concern. When students are required to read a chapter on the book or to research a report often they do not go beyond what's being required. In fact, results of the National Elementary Achievement Test (NEAT) as well as the National College Admission Examination (NCAE) showed that students in both elementary and high school still need to be guided on their appropriate reading materials to be utilized. The students would only read what they like to read.

Reading has been defined as a linear, procedural, routinized activity. Expert readers have been viewed as those who can master a discrete set of comprehension or skill, and with little effort, automatically apply them when reading (Sourcebook in English III, DECS - FAPE - PNU p.129).

Reading specialists give different views in reading, that it need is a complex process of perceiving graphic symbols and relating them to one's fund of experience. Teaching the students to read requires that every child receives excellent reading instruction and that children who are struggling with reading receive additional instruction from professionals especially prepared to teach them (International Reading Association). Ogeyik and Akway (2009) mentions that various studies carried out for determining reading habits of individuals report that a growing number of young people do not read for pleasure; boys enjoy reading less than girls (Clark \& Foster, 
2005);children from lower socio-economic backgrounds read less for enjoyment than children from more privileged social classes (Clark \& Akerman, 2006).

The students' reading preferences were also investigated for determining the reader profiles among the participant students (Ogeyik \& Akway, 2009). College student's refinement in reading is already expected by the teachers. Thus, it deemed right to believe that they are already equipped with the necessary knowledge structures, scripts and cognitive framework for comprehending texts in the content areas of science, literature, mathematics, social studies, arts and music as they were properly taught by their teachers. Students have already developed their reading power and are guided in the selection of reading materials (Umans, 1964:5) Özbay (2006) in Ogeyik and Akway (2009) disclose that reading is generally accepted as a way for reaching new information and assumed to be consistent with the comprehension capabilities of individuals.

Reading engagement, as such, is understood as a socially-mediated event (Arzubiaga, Rueda, \& Monzó, 2002). Sivan (1986) and Ames (1992) as cited in Arzubiaga, Rueda, and Monzó (2002) have begun to examine connections between social contexts and differential motivation. Access to books also implies that teachers should invite children to read by raising interest and curiosity about books and other materials (Gambrell, 2011). The daily family practices in which children participate may affect their access to school-based literacy activities; their notions of engagement and the organization of literacy practices; their appreciation of and interest in reading; and their idea of what counts as meaningful literacy (Arzubiaga, Rueda, \& Monzó, 2002).

To further contain a general view of students' reading ability there is a need to look into their reading preferences and performance. Somehow in the process there would be a revelation whether or not one affects the other. Cummins (1989) posits that at the initial stages of developing comprehension, learners will likely require materials which don't force heavy reliance on an unstable linguistic repertoire, but can provide for linguistic growth. Materials should afford a high level of predictability, confidence, through reliable context and visual cues. Thus, the choice of strategies must be made an integral part of the learning designs or activities considering how the students would work together or interact harmoniously while learning.

\section{Objectives of the study}

This research determined the reading preferences and performance of Freshmen education students of Cebu Normal University. Specifically, their reading preferences were identified and later verified, if these reading 
preferences affect reading performance. Challenges / opportunities which led to their interest were likewise looked into.

\section{Methodology}

A descriptive-normative survey method was utilized in the study. Likewise, the teachers' performance record of students as well as the validated researcher-made survey questionnaires were respectively utilized. These helped reveal the students' reading preferences and performance of the 556 First Year students of the Bachelor in Elementary Education and Bachelor in Secondary Education from the College of Teacher Education of Cebu Normal University. Respondents are assured that their responses are treated with utmost confidentiality as reflected in the consent form. The researchers strictly followed the ethical standards in research.These were treated using the simple percentage, and ranking by using MINITAB software.

\section{Results and discussion}

To arrive at the ranks of the reading preferences of the Freshmen Education students, responses were indicated: 1 as the highly preferred and 20 as the least preferred.

Table 1: Reading preferences of the freshmen BEED students in CNU

\begin{tabular}{|c|c|}
\hline \multicolumn{1}{|c|}{ Reading Preferences FICTION } & \multicolumn{2}{|c|}{} \\
\hline Shorts Stories & 4 \\
\hline Novels & 11 \\
\hline Plays & 13 \\
\hline Epics & 15 \\
\hline Ballads & 20 \\
\hline Cartoons and Comics & 14 \\
\hline \multicolumn{2}{|c|}{ NON FICTION } \\
\hline Magazines & 3 \\
\hline Newspapers & 2 \\
\hline Journals & 10 \\
\hline Essays & 12 \\
\hline Films and Videos & 6 \\
\hline GENERAL REFERENCES & 1 \\
\hline Dictionaries & 7 \\
\hline Encyclopedias & 17 \\
\hline Atlases & 18 \\
\hline Almanacs & 9 \\
\hline Internet Websites & 8 \\
\hline Bible & 19 \\
\hline Bibliography & 5 \\
\hline Textbooks & 16 \\
\hline Manuals & \\
\hline & \\
\hline & \\
\hline & \\
\hline & \\
\hline
\end{tabular}


Findings revealed that most first year education students preferred to read dictionaries followed by newspapers, magazines and others. This implies that these reading materials are considered indispensable as these students often use them not only for academic purposes but for pleasure as well. Nearly every magazine or newspaper gives informative and interesting features that are relevant and worth sharing. This often gives the "color" of these materials that is why most of the students often read them. In the process, they meet unfamiliar words, they immediately consult the dictionary for further understanding. In this generation of research, these students take advantage of any interesting and relevant topics therein for academic investigation. Reading for pleasure was another reason for selecting magazines as the preferred reading materials. Reading pleasurable books can be a great activity when they need a break for work or from worrying about their problems or all the assignments they may have to do.

On the other hand, findings disclosed the least preferred reading materials such as manuals, atlases, almanacs, bibliography and ballads. It is implied that these freshman students were not exposed to reading these materials. They may have some difficulties reading these materials possibly because they couldn't relate these with their actual life experiences unlike those which they often read. In one informal interview, a group of students uttered, "What we like most are the dictionaries, magazines, newspapers and sometimes short stories but not much the atlases, almanac, bibliography and ballads because they are not familiar to us and besides we often associate them with classroom tests."

Furthermore, this result is also supported by Kingston (1986) who stated "All lecturers make assumptions about their students' reading habits before coming to decisions about their reading needs for a particular course or topic. These assumptions relate to the speed and efficacy of the reading, the recognition and appreciation of the significance of the material to be read, as well as the availability of that material".

Table 2: Reading preferences of the freshmen BSED students in CNU

\begin{tabular}{|c|c|}
\hline Reading Preferences & Rank \\
\hline \multicolumn{1}{|c|}{ FICTION } & 5 \\
\hline Shorts Stories & 10 \\
\hline Novels & 16 \\
\hline Plays & 19 \\
\hline Epics & 9 \\
\hline Ballads & 15 \\
\hline Cartoons and Comics & 2 \\
\hline NON FICTION & 4 \\
\hline Mewazines & 13 \\
\hline Journals & 12 \\
\hline Essays & \\
\hline
\end{tabular}




\begin{tabular}{|c|c|}
\hline Films and Videos & 6 \\
\hline GENERAL REFERENCES & 3 \\
\hline Dictionaries & 1 \\
\hline Encyclopedias & 18 \\
\hline Atlases & 14 \\
\hline Almanacs & $\mathbf{8}$ \\
\hline Internet Websites & 11 \\
\hline Bible & 20 \\
\hline Bibliography & 7 \\
\hline Textbooks & 17 \\
\hline Manuals & \\
\hline
\end{tabular}

The results show that the first year BSED students highly preferred the encyclopedia, followed by magazines, dictionaries, and so forth and so on. The valuable reason why the respondents have probably preferred to read encyclopedia because they find it useful in conducting research and other school activities.

Cooper (1985) tested these theories in her own college sophomore classrooms. She surveyed students during the first class meeting to determine reading attitudes and experiences. From this, Cooper had students keep a reading journal in addition to many in-class writing assignments. She found that as they read the encyclopedia, magazines and the like, these students, "require similar abilities, similar analysis and synthesis, comparing and contrasting, connecting and reevaluating, the same weighing and judging of ideas". Therefore, the assumption could be made that what college students read has important implications for how they may interact with their other students and prospective teachers.

Different motives promote reading practice and reading habits among young children and adolescents ( Hussain \& Munshi, 2011). They added that freshmen interests and context can be considered to be the basic motives which urge them to acquire knowledge .

Freshmen were not so exposed to other reading materials such as plays, manuals, atlases, epics, and bibliography.. Convenience appeared to be the main factor in choosing a source of information as claimed by Chaudhry \& Low (2009). Freshmen do not have access to information using those materials but may found one from the internet which is natural and motivating. Chaudhry \& Low (2009) added that more than 90\% would look up information first on the internet, followed by magazines which provided up-to-date information on their topics of interest and friends were always a popular choice for quick information..

In the study of Chaudhry \& Low (2009), newspapers were the most preferred and a popular choice as preferred publication for reading as more than $70 \%$ respondents included newspapers in their reading repertoire. This 
denotes that people especially students use them daily for active engagement with the world.

Thus, engaging in early literacy activities should be a positive experience for students. When such is not the case, it is important for educators to realign their approach to supporting students in literacy events. As what (Chaudhry \& Low, 2009) said that reading is considered important to meet the need for information and personal development in addition to a leisure activity.

\section{Extent Which Reading Preferences Affect Reading Performance}

The results showed that the reading preferences of both First year BEED and BSED students don't have significant effect on their reading performance. This further shows that regardless of the students' reading preferences, their class performance is dependent on how they develop their competencies and apply these in real life situations and not on their reading preferences per se.

In order to have a full grasp on the students' varied experiences in reading, opportunities and challenges are herein noted.

Opportunities and Challenges on Student's Reading Experiences

One scholar has remarked, "The man who reads well is the man who usually thinks well; he has a basis for opinion and a touchstone for judgment."

Sometime around high school one's view of reading changes. The reader needs to take risks in order to grow in his/her ability to read, thus a supportive yet challenging atmosphere is needed. Upon reaching the collegiate level, learning experiences grow and certain realizations occur.

In an interview with students who were enrolled in Developmental Reading course, they expressed their gratitude to such an exposure. Group of students proudly said:

"At first we took Reading for granted until we were introduced to different strategies in reading which we really treasured not only because of the activities but also with the different reading materials we were exposed to.”

When asked to recall their experiences in the basic education, some uttered," We were not richly exposed to varied reading materials." With this note, it can be reflected that if these students would have been exposed to such during classroom discussions and in doing library work for certain purposes, these freshmen students would have been more challenged to read extensively and intensively which are very necessary conditions for comprehension. When they were told to share about their current reading experiences, many of them verbalized, "This is an opportunity for us to develop our comprehension skills like preparing for reading, gaining 
information while reading, predicting outcomes for learning, seeking to organize and recall that information, and interpreting the information from text. “

In terms of their interest in reading, some students individually shared their views. One said, "I am interested to read accounts of persons and events of the past because this can often enrich my understanding of the present. I am fascinated reading information and interpretation about important persons and developments of previous ages.”

"I love reading novels."

"I am interested about developments in the world that is why I read books in science, math, politics, arts, music, religion, philosophy and other adult areas of interest.”

"I like books by well-known authors whose works are considered an essential element to being a future teacher of reading"

"My friends, classmates, teachers, or parents often suggest books written by writers whose previous books have been found interesting and satisfying."

"I'm interested in books which have been made motion pictures."For me, I like books which are related to vocational interests which are both interesting and informative."

On the other hand, there were students who have met challenges in the past and even at present which may have probably affected their interest to read. Research on reading generally agrees that the most critical aspect of reading is how a child feels about reading. A threatening atmosphere is what creates non-readers and not their own lack of ability.

In an interview, some students who met challenges in their reading experiences disclosed, “We were forced to read even if we don't like to". Others frankly noted:

"We only read because our teachers would give us a test the following day." in school."

“ We love to read, but we don’t have reading materials at home even

" Sometimes even if we like to read but our parents want us to do the household chores. Reading should only be done in school."

"Our teachers don't allow us to read any material that we like but only those stories found in the textbooks."

"To read is to answer a test."

These utterances are reflective on the teacher's role in guiding the learner towards reading. Students would never be interested nor satisfied with any activity which they are forced to do. Conscious of teaching reading in order to learn, enjoy and apply skills to real life, teachers should allow 
students to pick their choice of material and not solely what is/are in the textbook/s. Likewise challenging reading activities may as well be provided for the widely-read students.

A wealth of research suggests that by framing learning with student interests in mind, teachers can increase student motivation and learning. Additionally, by understanding the varying literacy strengths and habits of students, teachers can identify what Vygotsky calls their "zone of proximal development" where literacy opportunities are not too hard as to frustrate or too easy to bore but just challenging enough to promote student learning. With a keen eye, one can observe the interests and strengths of students and, when possible, can consider these to plan learning opportunities for the students. By providing choice and respectful tasks, one can provide meaningful literacy experiences.

\section{Conclusion}

Students need both intrinsic and extrinsic motivation in order for them to learn, enjoy and apply the various reading skills in the development of critical thinking. Reading being a tool subject, if practiced daily, ushers students to achieve better performance not only in reading learning area but in other subjects as well.

\section{Recommendations}

The following are herein recommended:

1. Conduct a daily ten-minute non-graded pleasure reading activity where students choose any reading material they like..

2. Make a reading progress report regularly

3. Schedule a monthly library visit for the students to gather news updates from the print and non-print media.

\section{References:}

Abramson, R.F. (1979). Children's Favorite Picture Storybooks: An Analysis of Structure and Reading Preferences. (ERIC Documents Reproduction Service No. ED 17977)

Arzubiaga, R., Rueda, R., \& Monzó, L. (2002). Family matters related to the reading engagement of Latina/o children. Ann Arbor, 1001, 48109-41259.

Armbruster, Bonnei B. et al. (1983). The Role of Metacognition in Reading to Learn: A Developmental Perspective, Reading Education Report No. 40. Urbana, IL: Center for the Study of Reading. (ED 228 617)

Ashley, L.F. (1970). Children's Reading Interests and Individualized Reading. Elementary Engligh 47, n0. 80:1089-96.

Cooper, J. (1985). Reading literature analytically. In J. Cooper, R. Evans, \& E. Robertson (Eds.), Teaching college students to read analytically: An 
individualized approach (pp. 39-52). Urbana, IL: National Council of Teachers of English.Retrieved on March 18, 2014 from http://eric.ed.gov/?id=ED254835 March 18, 2014.

Chaudhry, A. \& Low, G. (2009). Reading Preferences among Different Generations: A Study of Attitudes and Choices in Singapore. Retrieved on August 2, 2012 from:http://www.las.org.sg/sjlim/SJLIM2009AbdusReading.pdf Hussain, I. \&Munshi, P. Flavell, John (1987). Theories of Learning in Educational Psychology. American Psychologist Retrieved on March 18, 2014 from http://www.lifecircles-inc.com/Learningtheories/constructivism/flavell.html March 18, 2014.

Gambrell, L. B. (2011). Seven rules of engagement: What's most important to know about motivation to read. The Reading Teacher, 65(3), 172-178.

Hussain, I. \&Munshi, P. (2011). Identifying Reading Preferences of Secondary School Students. Creative Education 2011. Vol.2, No.5, 429-434. DOI:10.4236/ce.2011.25062. Retrieved on November 11, 2011.

Jackobson, Erik, et.al. (2006). Creating Authentic Materials and Activities for the Adult Literacy Classroom: A Handbook For Practitioners. National Center for the Study of Adult Learning and Literacy.Retrieved on March 18, 2014 from http://www.ncsall.net/fileadmin/resources/teach/jacobson.pdf March 18, 2014.

Kingston, P. (1986). Teachers and books in the 1980s. In D. Baker (Ed.) Student reading needs and higher education (pp. 107-179). London: Library Association Publishing Ltd.

Kraaykamp , G. (2003). Literary socialization and reading preferences: Effects of parents, the library, and the school. Retrieved from: www.researchgate.net/...reading_preferences.../60b7d51a3a73cf2175.pdf

Mojica, Leonisa A. (2006). Reiterations in ESL Learners' Academic Papers: Do they contribute to lexical cohesiveness?The Asia-Pacific Education ResearchDecember 2006, 15(1), 105-125. Retrieved on January 12 , 2012 from http://www.dlsu.edu.ph/research/journals/taper/pdf/200612/MOJICA.pdf?ori gin=publication_detail

Ogeyik, M. and Akway, E. (2009). Investigating Reading Habits and Preferences of Student Teachers at Foreign Language Departments. The International Journal of Language Society and Culture.Retrieved on February 1, 2013 from, www.educ.utas.edu.au/users/tle/JOURNAL/on February 1, 2013.

Scliar-Cabral, Leonor. (Rumelhart 1976 and Singer 1983). Psycholinguistic Scientific and Technological Challenges 
Stern, David \& Huber Ganter (1981). $\quad$ Active Learing for Students and Teachers. Paris: PETER LANG

Thomas, Gracious (2010). Introduction to Social Work. Volume 2, New Delhi: MaidanGarhi: Ignou The People University

Villamin, Araceli (1994). Innovative Strategies in Teaching Reading. Quezon City: Phoenix Publishing House

Rachel F. (2008). "The implications of reading preferences of future educators". College Student Journal. Sept 2003. FindArticles.com. http://findarticles.com/p/articles/mi_m0FCR/is_3_37/ai_108836899

Spander, Katherine L. (1983). Reading Interest Versus Reading Preferences: Using the Research, The Reading Teacher.

uintana, C. (2001). "development and description of an inventory to measure the reading preferences of Mexican immigrant students, The". Bilingual Research Journal.Fall

Villamin, Araceli M. (1984). Innovative strategies in teaching reading. Quezon City,Philippines 